\title{
Práticas de leitura Na biblioteca: Nos CAMinhos DA LingǗ́STICA APLICADA*
}

\author{
Rita Rodrigues De SouZA* \\ Maria Aparecida Rodrigues De SouZa ${ }^{* * *}$
}

\section{RESUMO}

O presente artigo tem como objetivo relatar práticas de leitura e escrita, desenvolvidas na biblioteca e pautadas pelos conhecimentos da Lingüística Aplicada. No contexto escolar, esses conhecimentos transcendem as quatro paredes da sala de aula e passam a interessar, também, ao bibliotecário, importante mediador de leitura na escola. Por meio da Lingüística Aplicada, esse mediador do conhecimento re-significa a produção de leitura e escrita no espaço da biblioteca, interagindo com docentes, discentes e texto.

PALAVRAS-CHAVE: Lingüística Aplicada, biblioteca escolar, atividades, leitura, texto.

Reading practices in the library: in the ways of Applied Linguistic

\section{Abstract}

The present article has the aim of telling practices of reading and writing developed at the library and supported by the knowledge of Applied Linguistic. Sharing that at the school context these knowledges transcend the four walls of the classroom and they are also of interest of the librarian, important mediator of reading at school. By the Applied Linguistic, this mediator of knowledge reapplies the production of reading and writing at the library environment interacting with teachers, students and the text.

KeY wORDS: Applied Linguistics, school library, activities, reading, text.

Em 2001, a coordenação da Biblioteca Domingos Garcia Filho (BDGF) do Colégio Estadual Manoel Vilaverde, Inhumas-GO, escola de ensino médio, realizou um Censo de leitura por meio de aplicação de questionários com perguntas abertas e fechadas. E, conforme os dados

\footnotetext{
O relato foi apresentado em forma de painel no III Encontro Nacional do GELCO no dia 10 de outubro de 2006, em Brasília, pelas autoras do artigo.

** Mestre em Letras e Lingüística pela UFG, professora no Colégio Estadual Ary Ribeiro Valadão Filho e professora substituta de Língua Espanhola da Faculdade de Letras da UFG no período de 2005 a 2006. E-mail: ritarodrigues.souza@bol.com.br.

*** Bacharel em Biblioteconomia pela UFG, aluna da especialização em Gestão Educacional pelo Senac/GO e dinamizadora da Biblioteca do Colégio Estadual Manoel Vilaverde. E-mail: cirosou@bol.com.br.
} 
110 Revista Solta a Voz, v. 18, n. 1

obtidos, foi diagnosticado que seu acervo e serviços prestados eram subutilizados pela comunidade escolar, principalmente pelos alunos. Diante das informações, nós - mediadores do conhecimento na BDGF - elaboramos o projeto Minutos de leitura que se iniciou em 2002 e vem sendo reestruturado a cada ano, com novas metas e re-significando outras. Neste projeto, buscamos envolver a comunidade escolar como um todo: corpo docente, discente, equipe gestora; também, a comunidade. As atividades culturais e de pesquisa executadas no projeto visam ao desenvolvimento da leitura, de acordo com Braggio (1992), Moita Lopes (1996), Kato (1999) e Kleiman (2002). Essas atividades objetivam, ainda, desenvolver as habilidades de pesquisa, conforme Campello (2002, 2003a e 2003b), e a produção escrita, de acordo com Kaufman e Rodríguez (1998), Bonini (2001), Neves (2001) e Kleiman (2002) no contexto da biblioteca. Como produto das atividades culturais, oficinas de leitura, escrita, temos a produção de um jornal, o CEMsura (Souza e Souza, 2006).

Com a execução do projeto Minutos de leitura, proporcionamos aos usuários da BDGF a possibilidade de serem leitores e produtores de textos - por meio do jornal escolar, utilizando como suporte teórico Cavalcante (1999) -, como forma de ampliar a compreensão de mundo, de texto e de leitura. Pensamos que o texto jornalístico constitui-se em algo próximo, circulando notícias a todo tempo e em todos os lugares. Para Harris e Harris (1994, p. 5) "as notícias que nos chamam mais atenção são as mais próximas de nós: notícias da família, dos amigos, da escola e de nossa própria cidade". Assim, buscamos valorizar e ampliar os conhecimentos socioculturais dos discentes.

Com a finalidade de efetivar a função educativa da biblioteca e solucionar os problemas levantados, buscamos apoio nos teóricos da Lingüística Aplicada (LA) - no que se refere às concepções de leitura e texto - e na Biblioteconomia - no tocante às habilidades de pesquisa e produção textual na perspectiva do letramento. Com isso, nos propusemos a ampliar o canal de divulgação dos serviços e acervo da BDGF; estabelecer maior comunicação entre biblioteca e comunidade escolar; romper os paradigmas que impediam o trabalho em conjunto; mostrar, dessa forma, o valor das atividades da biblioteca para o enriquecimento das práticas escolares. E, conseqüentemente, motivar os alunos ao letramento informacional (Campello, 2003a) e a participar das atividades promovidas pela biblioteca, 
fazendo desta um espaço dinâmico por meio de atividades culturais, leitura e escrita, com a participação dos docentes e colaboradores da comunidade (profissionais da educação, escritores e estudantes universitários de várias áreas de conhecimento).

Ressaltamos que a participação dos docentes e dos colaboradores da comunidade em geral foi de máxima importância, porque proporciona a interdisciplinaridade, principalmente, entre a Biblioteconomia e a LA.

\section{LINGÜÍSTICA APLICADA NO CONTEXTO DA BIBLIOTECA ESCOLAR}

CRUZANDO CONHECIMENTOS: A LingÜÍSTICA APLiCADA

E AS PRÁTICAS PEDAGÓGICAS DO BIBLIOTECÁRIO

Uma das primeiras identificações da LA foi com pesquisas relacionadas ao ensino de línguas. Contudo, verificamos que isto, nos últimos anos, modificou e já existem pesquisas que ressaltam vários outros tópicos, tais como: "multilingüismo, testes, planejamento lingüístico, sociolingüística, psicolingüística, lexicografia, tradução, lingüística contrastiva, lingüística computacional, estilística, letramento, dentre outros." (Celani, 1992, p. 17, grifo nosso). Acreditamos que os conhecimentos da LA sobre o ensino de língua materna: leitura e escrita devem transcender a sala de aula de Língua Portuguesa. É necessário que constituam parte do repertório de outras áreas de conhecimento. A Biblioteconomia, por exemplo, representa um campo profícuo para essa aliança.

A LA, para nós, foi de suma importância para a compreensão da realidade e aplicação de novos conhecimentos com o objetivo de intervir no processo de ensino/aprendizagem da leitura e escrita na biblioteca de forma consciente. A prática de leitura na escola, ainda, está muito distante de ser o que muitas teorias estabelecem e o que nós, mediadores desse processo, almejamos. Entretanto, nossa postura de enfrentamento do problema casase com a metáfora de Kaplan (1980, p.10 apud Celani,1992, p.19):

a LA constitui o ponto no qual todo o estudo da linguagem se encontra e se torna realidade [metáfora]. A partir de uma interpretação multidisciplinar para a solução de problemas relacionados à linguagem, de uma redefinição sempre nova para cada novo conjunto de problemas, a LA adquire uma autonomia organizacional que lhe justifica o uso do nome como área de direito próprio. 
112 Revista Solta a Voz, v. 18, n. 1

Talvez, em conseqüência do caráter eminentemente prático na definição do objeto de estudo da LA é que a rotulem como essencialmente prática. Entretanto, este fato não "impede que seus estudos sejam totalmente teóricos, descritivos, explicativos" (Bastos e Mattos, 1993, p. 18). Assim que, sem a pretensão de estarmos totalmente corretas, buscamos nesse viés explicativo da LA, obter maior compreensão do contexto crítico que nos circunda.

A colaboração entre usuários, lingüista e profissionais das áreas pertinentes, conforme Celani (1992), é crucial, não só para a identificação de problemas com mais clareza, mas também para preencher os espaços entre identificação e solução de problemas. Por isso, partimos dos dados obtidos na pesquisa, como ponto inicial para a busca de apoio teórico que nos ajudasse a compreender a realidade.

Segundo Campello (2002, p. 99), "há muito tempo a biblioteca deixou de ser considerada apenas como um local de preservação de livros e informações e passou a ser vista numa perspectiva educativa, isto é, como espaço de construção de conhecimento". Concordamos com Campello (2002, p. 100), que simplesmente disponibilizar de "um acervo bem formado e adequado aos programas curriculares da escola não é suficiente para propiciar uma aprendizagem [...] duradoura e que dê ao aluno condiçôes de aprender de forma independente". É necessário que a biblioteca faça seu planejamento com atividades graduais e progressivas com vistas a atender tanto conteúdos curriculares quanto às reais necessidades de letramento dos usuários.

As práticas da biblioteca devem ir além das necessidades informacionais da comunidade envolvida no processo ensino/aprendizagem. Ela deve ser um espaço de prática pedagógica trabalhando em parceria: bibliotecários, corpo docente e colaboradores, a fim de que as atividades propostas atinjam sua meta de formadora de cidadão crítico e com práticas significativas de leitura e escrita.

Tomando por base as orientações curriculares para o ensino médio (Brasil, 2006), a biblioteca se enquadra perfeitamente no propósito de dar suporte à continuidade de aprofundamento e solidificação de saberes para o aluno, nessa etapa de sua vida acadêmica, por apresentar atividades de natureza ao mesmo tempo social e cognitiva, co-construída entre sujeitos. E ainda, complementando o pensamento, os sujeitos cujas experiências se constroem num espaço social e num tempo histórico, as atividades de uso 
da língua e da linguagem, assumem propósitos distintos e, conseqüentemente, diferentes configurações marcadas pelo contexto sócio-histórico.

No bojo das reflexões aqui desenvolvidas, ressaltamos que a assunção de uma postura interdisciplinar no âmbito da biblioteca é uma metodologia necessária. Nesse caso, trata-se de projetos que apostam na atividade de conhecer/aprender um dado objeto organizado sistematicamente. Isto é, projetos advindos do conjunto de disciplinas escolares que compóem o currículo ou de diferentes áreas do conhecimento. No que se refere à leitura e escrita na biblioteca escolar, um olhar especial para a Biblioteconomia em consonância com a LA.

Desta maneira, as concepções de leitura, escrita e texto da LA ao ensino de língua materna constituem conhecimentos relevantes para um melhor desempenho dos mediadores da leitura na biblioteca. O que corrobora com os conhecimentos que Campello (2002) nos oferece com relação às necessárias mudanças de prática pedagógica dos bibliotecários frente aos processos de leitura e habilidades de pesquisa. Ela nos remete, ainda, à questão do planejamento de atividades de forma reflexiva e interdisciplinar.

\section{RE-SIGNIFICANDO AS PRÁTICAS DE LEITURA E ESCRITA NO CONTEXTO DA BIBLIOTECA}

Ao observar o trabalho com a leitura na escola, percebemos que essa assume um valor pragmático, no sentido restrito dessa palavra, ou seja, prático. Essa conotação expressa o poder que uma classe social detém sobre outra, uma vez que reflete intençôes ideológicas e econômicas subjacentes, conforme Zilberman e Silva (2000). Para esses estudiosos da função social da leitura, esta vem sofrendo um distanciamento do seu objeto, que é o texto; e, nesse processo, a leitura incorpora um caráter prático, valorizado pela classe dominante: aprender a ler para vencer e prosperar na vida e não para o indivíduo conhecer e participar conscientemente da estrutura social na qual vive. Conforme Zilberman e Silva (2000) a leitura, nesse sentido, torna-se um meio de reprodução do status quo e não de libertação.

Segundo Mey (2001, p. 226), um leitor demonstra sua competência lingüística quando é capaz de efetuar corretamente as relações entre os elementos textuais como "pronomes, dêiticos, sujeitos de verbos, recompor frases na ordem direta, estabelecer a interpretação a partir da relação entre elementos sintáticos e semânticos”. Entretanto, o leitor só será realmente 
114 Revista Solta a Voz, v. 18, n. 1

competente à medida que for hábil para realizar a atividade de leitura como um ato de cooperação que concebe a compreensão do texto como um processo de interação (Moita Lopes, 1996; Mey, 2001).

A leitura como interação possibilitará ao leitor tornar-se consciente de que o encontro com o texto representa um encontro com a expressão sócio-histórica e cultural de quem o escreveu. Mey (2001, p. 228) configura esse processo interativo como um "ato pragmático de leitura [que] implica um convite em aberto ao leitor para unir-se ao autor na co-criação de sua história, preenchendo as lacunas que o texto deixa abertas". Diferentemente do conceito restrito praticado em muitas escolas.

De acordo com Braggio (1992) e Kato (1999), a capacidade pragmática do uso da linguagem inicia-se desde os primeiros anos de vida da criança, em que essa interage ativamente com o mundo por meio da linguagem. Braggio (1992, p. 22) expõe de forma clara que, mesmo a criança tendo a predisposição inata para o aprendizado e aquisição da leitura, a "capacidade do leitor de predizer, confirmar, rejeitar e refinar o que lê baseia-se no seu conhecimento da estrutura lingüística, seu estilo cognitivo e experiência com o material escrito". Isso nos leva a creditar uma importância à maneira como a escola está tratando o material escrito em relação ao aluno. Os estudos de Braggio (1992) nos mostram que quanto mais mecânico for o aprendizado da leitura, menos teremos um leitor envolvido nesse processo, e menos ainda teremos uma leitura como um ato pragmático definido por Mey (2001), uma vez que se valoriza a decodificação em detrimento da construção do significado do texto.

No Brasil, já se percebem, claramente, manifestaçôes dos bibliotecários sobre a necessidade de ampliar a ação pedagógica da biblioteca, visando a formação de leitores críticos e autônomos. Para que isso ocorra, se faz necessário pôr em prática a concepção de competência informacional que está intimamente ligada à competência de leitura. Desse modo, desenvolveremos a habilidade de ler e usar informação necessária para a vida cotidiana. No que diz respeito à biblioteca escolar, devemos essencialmente levar em conta o panorama dos estudos sobre letramento, que é "a capacidade de ler e escrever" (Trask, 2004, p. 154). Ou melhor, "o estado ou condição de quem não apenas sabe ler e escrever, mas cultiva e exerce as práticas sociais que usam a escrita" (Soares, 2001, p. 47).

Compartilhamos com os teóricos que defendem que a prática de leitura não pode se constituir de um conjunto reduzido de atividades me- 
cânicas de decodificação de sons e letras, mas envolver outras estratégias para trabalhar as habilidades de selecionar, antecipar, inferir e confirmar hipóteses. E a biblioteca escolar como subsistema não pode ignorar que

passa a ser essencial, atendendo à necessidade de uma aprendizagem baseada em textos numerosos, diversificados e autênticos [...]. É preciso que ela dê contribuição efetiva para uma ação educativa que extrapole a sala de aula e permeie toda a vida do aluno, avançando para um patamar além de espaço de apoio à aprendizagem, transformando-se em participante ativa na construção do conhecimento (Campello, 2002, p. 103-104).

Três são os pontos que constituem a base sobre a qual a biblioteca deve se ancorar para estabelecer suas metas pedagógicas, de acordo com Campello (2003b): a leitura, a pesquisa escolar e a cultura, para que a biblioteca cumpra com a sua função de letramento informacional. Este letramento constitui o desenvolvimento de habilidades de localizar, selecionar, interpretar, utilizar e comunicar informação de maneira crítica e responsável, que pode contribuir para a graduação da capacidade de leitura e escrita de jovens - nosso objeto de interesse neste estudo -, instrumentalizando-os para o "acesso aos saberes lingüísticos necessários ao exercício da cidadania” (Campello, 2003b, p. 12).

Em relação aos conhecimentos sobre a leitura, é fato que as pesquisas lingüísticas, neste campo, têm sido frutíferas, isso possibilita a nossa compreensão das dificuldades de leitura apresentadas pelos jovens. Desta forma, os mediadores de leitura na biblioteca podem ampliar efetivamente seus campos de atuação. Abrem-se, portanto, para os bibliotecários, possibilidades de ações mais efetivas, a partir do momento em que a leitura seja compreendida em suas inúmeras dimensões, proporcionando autonomia na aprendizagem. Portanto, "professores e bibliotecários deverão contribuir como mediadores na formação e no desenvolvimento do leitor, crítico e criativo" (Garcez e Carpes, 2006, p. 65).

\section{O TEXTO E AS PRÁTICAS DE LEITURA}

O QUE É LEITURA?

A imaginação, a alegria, o conhecimento, tudo isso pode ser proporcionado por meio do processo de leitura. Mas, para que isso ocorra, este processo pressupõe interação entre o texto, leitor e autor. $\mathrm{O}$ ato de 
116 Revista Solta a Voz, v. 18, n. 1

leitura, assim configurado, remete-nos à idéia de leitura como um processo comunicativo contínuo de construção e atualização de sentidos. Diante disso, leitura, na nossa concepção, representa o ato de construir sentidos de forma crítica e comunicativa, em que texto e leitor se modificam por meio da interação (Souza, R., 2004).

Segundo Marcuschi (1996) e Coracini (2002), a construção do sentido, por meio da leitura, concretiza-se com a interação da experiência e do conhecimento lingüístico e extralingüístico do leitor com o texto. Para esses estudiosos, os sentidos não estão prontos no texto e nem são prévios à leitura, são construções que se edificam com a participação do leitor. Flores et al (1999, p. 56) consideram que a leitura como "interação resulta em uma reconstrução individual ou coletiva de sentidos" e se constitui num momento de grande riqueza em que os alunos devem compartilhar suas opiniōes com seus colegas e/ou mediadores da leitura.

Nós, mediadores da leitura, temos como função educativa, também, a interação texto/leitor. Para isso, precisamos necessariamente de ser leitores competentes e formar outros leitores, também, competentes. Isto é, que sejam capazes não só de abstrair os significados importantes de um texto, mas interagir com eles de forma cooperativa, usando conhecimentos prévios com a finalidade de se posicionar de maneira crítica e consciente (Mey, 2001).

Conforme as estratégias usadas no processamento da leitura, esse pode ser denominado basicamente de interativo, que corresponde ao uso de dois tipos de estratégias: Bottom-up, ascendente, e Top-down, ou descendente (Kleiman, 2002).

$\mathrm{Na}$ prática de leitura ascendente, o leitor se aproxima do texto por meio de pequenas unidades (letras, palavras, frases, sentenças etc.) e esse procedimento de aproximação do texto passa a ser automático. Dessa maneira, os leitores praticam a leitura de forma inconsciente e decodificar passa a ser uma prática fundamental.

$\mathrm{Na}$ leitura descendente, o leitor adequa o texto aos seus conhecimentos culturais, sintáticos, lingüísticos e/ou históricos; depois volta ao texto para confirmar suas expectativas de leitura ou verificar se aparece uma informação nova. Concebe, assim, a leitura como verificação de informaçōes.

Já a prática interativa consiste no processo de leitura em que a construção do significado do texto se realiza pela interação entre leitor e texto. O êxito deste processamento da leitura depende do tipo de texto, bem 
como, do conhecimento de mundo do leitor, do nível de proficiência lingüística, da motivação para ler o texto, do uso de estratégias e das crenças culturalmente formadas sobre o que significa ler. A leitura praticada dessa maneira seria a leitura como interação.

Moita Lopes (1996, p. 137) afirma que o modelo de leitura é interativo no sentido de que as informações, na forma de esquemas, são negociadas entre leitor e escritor "num ato comunicativo, ou seja, na perspectiva de como a linguagem é usada na interação comunicativa entre os participantes no discurso". Segundo Moita Lopes (1996), esquemas são estruturas cognitivas armazenadas em unidades de informação na memória de longo prazo, e nós as ativamos quando lemos. Essas informações são conhecimentos parciais sobre assuntos, situações, eventos típicos de nossa cultura que determinam, em grande parte, as nossas expectativas sobre a ordem natural das coisas (Kleiman, 2002). Também, esses esquemas podem se automodificar à medida que aumentam ou alteram o nosso conhecimento de mundo (Kato, 1999).

Observa-se que os modelos de leitura Bottom-up e Top-down tornamse improdutivos se praticados isoladamente. Há de retomá-los na prática diária de leitura como suporte para uma leitura interativa e pragmática. Esses conhecimentos devem permear as práticas de leitura realizadas na biblioteca de modo que esta cumpra sua função de formar um leitor crítico e autônomo.

A concepção de leitura que adotamos em nosso projeto é a interativa que supera a leitura como decodificação de letras, palavras e sentenças. É, sobretudo, leitura como construção do significado, numa perspectiva de interação entre estes dois mundos: o leitor e o autor do texto. Consideramos, ainda, que esse tipo de leitura parece ser útil para que o leitor se modifique e também transforme sua realidade circundante (Braggio, 1992; Moita Lopes, 1996; Flores et al, 1999; Mey, 2001).

Diante desse estudo, fizemos uso dos conceitos da LA para buscar novas práticas de leitura na biblioteca. A nossa primeira atividade para levantamento de dados sobre leitura como prática social foi a realização das oficinas de leitura e produção de textos propostas no projeto Minutos de leitura. Após as atividades, foi distribuído, aos 25 participantes, um questionário com duas perguntas abertas sobre leitura.

Citamos alguns dos conceitos de leitura (CL) apresentados pelos alunos no questionário aplicado. Recortamos os fragmentos relevantes 
118 Revista Solta a Voz, v. 18, n. 1

para o nosso trabalho e tabulamos em porcentagem a quantidade que esses conceitos aparecem nas respostas. Ressaltamos, contudo, que a nossa análise foi qualitativa e esses dados serviram como norteador secundário.

Tabela 1 - Concepções de leitura dos alunos

\begin{tabular}{llc}
\hline CL & Conceito de leitura dos alunos & Porcentagem \\
\hline CL1 & $\begin{array}{l}\text { "Ler é aprofundar o meu conhecimento, conhecer } \\
\text { novas culturas." }\end{array}$ & $40 \%$ \\
CL2 & $\begin{array}{l}\text { "Ler é adquirir conhecimento." } \\
\text { CL3 }\end{array} \quad \begin{array}{l}\text { "Leitura é um modo de sair um pouco desse mundo de } \\
\text { violência [...] é viajar no meu pensamento." }\end{array}$ & $16 \%$ \\
CL4 & $\begin{array}{l}\text { "Ler é aprender e conhecer mais coisas para subir na } \\
\text { vida." }\end{array}$ & $4 \%$ \\
CL5 & "Ler é uma forma de preparar melhor para a vida." & $4 \%$ \\
\hline
\end{tabular}

Fonte: As autoras

Os CL, citados na tabela 1 , foram retirados dos questionários respondidos após a oficina "Leitura: mais que um instrumento de trabalho, uma prática para a vida", realizada na terceira edição do Projeto Minutos de leitura. Por meio dos conceitos citados e outros não mencionados, pudemos inferir algumas concepções de usos da leitura desses alunos, egressos do ensino fundamental. Citamos: Ler para aprender; conhecer; informa-se; aumentar a criatividade; entreter-se; ficar inteligente; preparar-se para a vida; prestar vestibular; ter uma boa cultura; melhorar de vida; melhorar a fala e a escrita.

\section{O Que É TEXTO?}

Há várias definições de texto na literatura especializada. Kleiman (2001, p. 17-18), apresenta duas definições de texto que, embora legitimadas pelas práticas escolares, segundo a autora, estão equivocadas: "o texto como um conjunto de elementos gramaticais" e "o texto como repositório de mensagens e informaçōes".

O desenvolvimento do aluno em relação à capacidade de análise dos recursos expressivos da linguagem, considerando textos/contextos nas condiçōes de produção e recepção, deve ser construído no decorrer da sua vida acadêmica, a partir das séries iniciais ao final do ensino médio e é necessário que essa capacidade de ler, reler e construir significados o acompanhe por toda 
sua vida. Assim, é necessário que haja "o aprofundamento dos conhecimentos como meta de continuar aprendendo; o aprimoramento do aluno como pessoa; e a formação ética e o desenvolvimento da autonomia intelectual do pensamento crítico com flexibilidade" (Brasil, 1999, p. 138). Pois, assim ele saberá como ler tanto textos que se propóem informar, entreter, argumentar quanto persuadir; presentes no meio escolar ou extra-escolar (Paulino et al, 2001).

Para Paulino et al (2001) e Grigoletto (2002), não é suficiente introduzir uma diversidade de textos na escola, é necessário, também, levar os alunos a perceberem os vários sentidos que um só texto pode apresentar e que cada tipo de texto exige uma recepção distinta, que deve ser ensinada, pois "se os textos se diversificam, também as leituras devem ser diferentes" (Paulino et al, 2001, p. 156).

Em consonância com a concepção de leitura, adotada em nosso projeto, que é a leitura como capacidade do leitor de se transformar à medida que interage com o texto, de maneira crítica; é que consideramos pertinentes para nosso trabalho as definições que seguem:

a) "O texto, produto da atividade verbal humana, é uma unidade semântica, de caráter social, que se estrutura mediante um conjunto de regras combinatórias de elementos textuais oracionais, para manifestar a intenção comunicativa do emissor" (Kaufman; Rodríguez, 1998, p. 165);

b) "A unidade básica da comunicação humana é o texto que pode ser definido, de modo amplo, como um conjunto de elementos lingüísticos que detém caráter de totalidade comunicativa em função de fatores lingüísticos, semânticos e pragmáticos” (Bonini, 2001, p. 12).

c) "O texto é, ao mesmo tempo, organização da informação, organização da interação e organização semântica” (Neves, 2001, p. 69);

d) "O texto é [...] uma unidade semântica, onde, vários elementos de significação são materializados através de categorias lexicais, sintáticas, semânticas, estruturais" (Kleiman, 2002, p. 45);

Em síntese, conforme Kaufman e Rodríguez (1998), Bonini (2001), Neves (2001) e Kleiman (2002), o texto é uma unidade lingüística significativa, constituída de forma organizada por uma base lingüística (categorias lexicais, sintáticas, semânticas e estruturais) e por elementos extralingüísticos. Kaufman e Rodríguez (1998) denominam estas duas bases de organização da unidade lingüística de elementos cotextuais e elementos contextuais, respectivamente. E estes elementos - cotextuais e contextuais - se relacionam para materializar as intençôes do autor em confronto com o sujeito leitor (Mey, 2001). 
120 Revista Solta a Voz, v. 18, n. 1

O trabalho com o texto precisa se constituir num processo de reconstrução do mesmo e não a simples descrição de seus componentes. Para que essa reconstrução ocorra, há que se atribuir importância aos diferentes tipos de textos e às diferentes leituras que o leitor poderá fazer. Pois, segundo Zilberman e Silva (2000, p. 115) "uma pedagogia da leitura de cunho transformador propõe, ensina e encaminha a descoberta da função exercida pelo(s) texto(s) num sistema comunicacional social e político”.

Definido os conceitos de texto (CT) pelos teóricos acima, desenvolvemos uma segunda atividade que foi a percepção do que é texto pelos alunos. A seguir, apresentamos alguns CT, segundo a concepção dos alunos redatores do CEMsura, que foram coletados por meio da aplicação de questionários com duas perguntas abertas.

Os fragmentos dos CT que seguem foram relevantes para o nosso estudo e os tabulamos em porcentagem. Esses dados quantitativos foram analisados de forma qualitativa, conforme dados da tabela a seguir.

Tabela 2 - Conceitos de texto dos alunos

\begin{tabular}{|c|c|c|}
\hline CT & Conceito de texto dos alunos & Porcentagem \\
\hline CT1 & $\begin{array}{l}\text { "[...] são palavras que se organizam formando um sentido } \\
\text { para expressar uma idéia, contar uma história, etc." }\end{array}$ & $32 \%$ \\
\hline CT2 & $\begin{array}{l}\text { "[...] é uma parte da literatura, onde a pessoa pode expressar } \\
\text { sentimentos, contar uma história. O texto também pode } \\
\text { ser condutor de uma música, um poema, etc." }\end{array}$ & $24 \%$ \\
\hline CT3 & $\begin{array}{l}\text { "[...] é uma prática da leitura de bons autores que compete } \\
\text { produzir determinados fins escolares ou profissionais. Tex- } \\
\text { to se discute uma fórmula mágica que exercitamos nossos } \\
\text { conhecimentos." }\end{array}$ & $20 \%$ \\
\hline CT4 & $\begin{array}{l}\text { "[...] é uma história verdadeira ou criativa que pode ser } \\
\text { colocada em livros para ser lidos por aluno." }\end{array}$ & $16 \%$ \\
\hline CT5 & $\begin{array}{l}\text { “[...] é descoberta, e descoberta é prazer. Toda alma, todo } \\
\text { espírito, tem vontades, tem desejos. Um texto é na verdade } \\
\text { o expressar de todos esses sentimentos que a alma insiste } \\
\text { em pulsar na simplicidade de outros, palavras, frases e ora- } \\
\text { ções, permeia uma parte de quem o cria, de quem o tece. } \\
\text { Além de eternizar um instante, um texto também nos pa- } \\
\text { rece a coragem de quem escreve e se conhece." }\end{array}$ & $8 \%$ \\
\hline
\end{tabular}

Fonte: As autoras. 
Contrastando as informaçōes sobre o que é leitura e texto, que os alunos nos forneceram, pudemos observar que eles deixam transparecer, por meio do discurso, que têm uma perspectiva muito boa em relação aos usos da leitura e da escrita. Porém, percebemos que há uma contradição no que se refere à prática. Pois, como os discentes pensam tudo isso da leitura, se ainda subutilizavam a biblioteca? Mesmo que no discurso tenha prevalecido o sentido pragmático - ler para aprender conteúdos escolares. Já em relação ao que é texto é evidente que há uma sobreposição de conceitos. Não se sabe se os alunos estão falando de leitura ou texto. Eles valorizam a palavra escrita, principalmente a literatura; e parecem desconhecer outros textos.

A partir destas contradições é que o projeto de leitura buscou trabalhar atividades culturais para mostrar que o conhecimento é uma conquista para a vida toda. Esse projeto resulta na produção bimestral do CEMsura.

\section{Construindo a LeITURA E A ESCRITA: o JORnAl CEMsura}

Dentre as atividades culturais que denominamos Minutos de leitura, desenvolvemos: bate-papo com escritores inhumenses, palestra com historiadores sobre as origens e fatos históricos locais; oficina de leitura e escrita ministradas por colaboradores (estudantes universitários, profissionais da educação e de Letras); oficina de contação de histórias que culmina na Fornada literária, trabalho com a dramaturgia e o folclore. Às vezes, os textos produzidos nas oficinas já se tornam matérias a ser publicadas nas edições. Essas atividades não são realizadas esporadicamente, e sim de forma sistemática e planejadas ao longo do calendário escolar, inseridas no Projeto Político Pedagógico.

Para a produção do CEMsura se faz necessária a formação da equipe de trabalho que engloba tanto representantes do corpo docente quanto discente, funcionárias da BDGF. E, também colaboradores para ministrar oficinas de produção de textos e dinâmicas de entrosamento entre os usuários da biblioteca (Souza e Souza, 2006). Composta a equipe, partimos para os encontros quinzenais coordenados pela BDGF para definirmos as seçôes, os assuntos, distribuir tarefas (lembrando que ocorre a rotatividade de pessoas envolvidas na produção de cada edição), discutir o material e o que deverá ser publicado, produção de textos/ilustraçōes, definição de títulos e páginas e, finalmente, sua diagramação. 
122 Revista Solta a Voz, v. 18, n. 1

Entre o processo de elaboração do jornal até a sua circulação o objetivo principal do projeto se concretiza através da troca de experiência entre mediadores da leitura e usuários. Com isso, há a mudança na relação usuário/leitura/texto, eleva-se o nível de letramento informacional do aluno e o faz sentir-se parte integrante desse contexto social.

\section{ConsideraçôES}

A leitura pode ser considerada uma prática de linguagem que vai além do processo de decodificação, por vários motivos: o ato de ler faz história na cultura, o texto escrito sofre modos diferentes de acesso, o leitor é construído pela sua história em relação ao letramento (Souza, A., 2004). Essa perspectiva nos auxilia a entender algumas deficiências do trabalho feito com leitura no âmbito da biblioteca escolar. Ainda nos encontramos distante de um paradigma que dê conta do leitor que, ao apropriar-se criticamente da linguagem escrita, reflita e atue sobre sua realidade (Braggio, 1992). Porém, somos conscientes também que nosso trabalho tem apresentado resultados significativos na nossa interação com o aluno e o enriquecimento das produçôes deles. Isso confirma que a Biblioteconomia se constitui pela sua prática, pressupõe o alargamento de sua função educativa através da leitura, escrita e cultura (Campello, 2002).

Oferecer atividades planejadas, sistemáticas e constantes representa a função da biblioteca, embora isso não seja de conhecimento de muitos que atuam nela. A idéia de promover a interdisciplinaridade por meio dos conteúdos curriculares, unindo habilidades de localização de informaçóes e a interpretação das mesmas (Campello, 2002, 2003a, 2003b), compõe o conjunto de funçóes da biblioteca. Os mediadores da leitura, neste contexto, devem acoplar às suas habilidades informacionais as teorias da LA para a busca de soluçōes de problemas com relação ao ensino de leitura e escrita. Não que queiramos assumir o papel do professor. Mas, tão somente, contribuir para a formação de um cidadão mais competente no uso da linguagem. Sendo assim, desejamos assumir um papel significativo neste processo. Não somente guardiōes de livros.

Neste contexto, a interação bibliotecário e professor é de suma importância para a concretização das funções educativas da biblioteca com relação ao ensino/aprendizagem da leitura e escrita. Esse tipo de comportamento é o que valoriza cada sujeito dentro do processo ensino/aprendi- 
zagem. A BDGF, dessa forma, deixa para trás suas características de passividade e isolamento das atividades desenvolvidas no contexto escolar. Ajuda a re-significar as práticas sociais de leitura e escrita.

Desenvolvemos este projeto de leitura da BDGF por acreditar que o papel da mesma não se restringe à função didático-pedagógica, ou seja, o de dar apoio para o programa dos professores. Cumpre-se assim, a função da biblioteca de proporcionar ambientes que dêem condiçôes de ler, tentar despertar os jovens para as potencialidades da escrita, prepará-los para as competências de leitura - enfim, providenciar que o espaço da biblioteca seja um espaço que promova verdadeiramente o ato de ler.

\section{REFERÊNCIAS}

BASTOS, L. K. X.; MATTOS, M. A. B. de. A Lingüística Aplicada e a Lingüística. Trabalhos em Lingüistica Aplicada, Campinas, n. 22, p. 7-24, jul./dez. 1993.

BONINI, A. Ensino de gêneros textuais: a questão das escolhas teóricas e metodológicas. Trabalhos em Lingüistica Aplicada, Campinas, n. 37, p. 7-23, jan./jun. 2001.

BRAGGIO, S. L. B. Leitura e alfabetização: da concepção mecanicista à sociopsicolingüística. Porto Alegre: Artes Médicas, 1992.

BRASIL. Ministério da Educação. Parâmetros Curriculares Nacionais: ensino médio. Brasília: Secretaria de Educação Média e Tecnológica/MEC, 1999.

- Secretaria de Educação Básica. Linguagens, códigos e suas tecnologias. Brasília: Ministério da Educação, 2006. (Orientações curriculares para o ensino médio; v. 1).

CAMPELLO, B. A biblioteca escolar como espaço de construção do conhecimento. In: CONGRESSO INTERNACIONAL DE ARQUIVOS, BIBLIOTECAS, CENTROS DE DOCUMENTAÇÃO E MUSEUS, 1., 2002, São Paulo. Textos. São Paulo: Imprensa Oficial, 2002. p. 99-106.

O movimento da competência informacional: uma perspectiva para o letramento informacional. Ciência da Informação, Brasília, v. 32, n. 3, p. 28-37, set./dez. 2003a. 
124 Revista Solta a Voz, v. 18, n. 1

CAMPELLO, B. A função educativa da biblioteca escolar no Brasil: perspectivas para o seu aperfeiçoamento. In: ENCONTRO NACIONAL DE PESQUISA EM CIÊNCIA DA INFORMAÇÃO, 5., 2003, Belo Horizonte. Anais. Belo Horizonte: ECI, UFMG, 2003b. CD-ROM.

CAVALCANTE, J. O jornal como proposta pedagógica. São Paulo: Paulus, 1999.

CELANI, M. A. A. Afinal, o que é lingüística aplicada? In: PASCHOAL, M. S. Z. de; CELANI, M. A. A. Lingüistica Aplicada: da aplicação da lingüística à lingüística transdisciplinar. São Paulo: EDUC, 1992. p. 15-23.

CORACINI, M. J. R. F. Leitura: decodificação, processo discursivo...? In: (Orgs.). O jogo discursivo na aula de leitura: língua materna e língua estrangeira. 2. ed. Campinas, SP: Pontes, 2002. p. 13-20.

FLORES, C. N. et al. Hacia una nueva práctica de lectura. Anuário Brasileño de Estúdios Hispânicos, Brasília, n. 9, p. 53-58, 1999.

GARCEZ, E. F.; CARPES, G. Gestão da informação na biblioteca escolar. Revista ACB: Biblioteconomia em Santa Catarina, Florianópolis, v. 11, $\mathrm{n}$. 1, p. 53-73, jan./jul. 2006.

GRIGOLETTO, M. A concepção de texto e de leitura do aluno de $1^{\circ} \mathrm{e}$ $2^{\circ}$ graus e o desenvolvimento da consciência crítica. In: (Org.). $O$ jogo discursivo na aula de leitura: língua materna e língua estrangeira. 2. ed. Campinas, SP: Pontes, 2002. p. 85-92.

HARRIS, R.; HARRIS, C. Faça seu próprio jornal. 3. ed. São Paulo: Papirus, 1994.

KATO, M. A. O aprendizado da leitura. 5. ed. São Paulo: Martins Fontes, 1999.

KAUFMAN, A. M.; RODRÍGUEZ, M. E. La escuela y los textos. Buenos Aires: Santillana, 1998. Aula 21.

KLEIMAN, Â. Oficina de leitura: teoria e prática. 8. ed. Campinas, SP: Pontes, 2001.

Texto e leitor: aspectos cognitivos da leitura. 8. ed. Campinas, SP: Pontes, 2002.

MARCUSCHI, L. A. O livro didático de língua portuguesa em questão: o caso da compreensão de texto. Caderno do I Colóquio de Leitura do 
Centro-Oeste, Departamento de Estudos Lingüísticos e Literários FL/ UFG, Goiânia, n. 11, p. 38-71, nov. 1996.

MEY, J. L. As vozes da sociedade: seminários de pragmática. Campinas, SP: Mercado de Letras, 2001.

MOITA LOPES, L. P. da. Um modelo interacional de leitura. In: Oficina de lingüistica aplicada: a natureza social e educacional dos processos de ensino-aprendizagem de línguas. Campinas, SP: Mercado de Letras, 1996. p. 137-146.

NEVES, M. H. de M. A gramática funcional. São Paulo: Martins Fontes, 2001.

PAUlinO, G. et al. Tipos de texto, modos de leitura. Belo Horizonte: Formato Editorial, 2001.

SOARES, M. Letramento: um tema em três gêneros. 2. ed. Belo Horizonte: Autêntica, 2001.

SOUZA, A. P. de. Leitura no ensino médio: uma análise discursiva. In: ENCONTRO NACIONAL DO GELCO, 2., Goiânia, 2004.

SOUZA, R. R. de. Sobre $o$ ato de ler: em questão as atividades de leitura propostas nos livros didáticos de E/LE. 2004.160 p. Dissertação (Mestrado em Lingüística Aplicada) - Faculdade de Letras, Universidade Federal de Goiás, Goiânia, 2004.

SOUZA, R. R. de; SOUZA, M. A. R. de. A Biblioteca Domingos Garcia Filho: espaço de criação e disseminação cultural. In: SIMPÓSIO DE ESTUDOS E PESQUISAS DA FACULDADE DE EDUCAÇÃO DA UNIVERSIDADE FEDERAL DE GOIÁS, 4., 2006, Goiânia. Anais eletrônicos... Goiânia, 2006. (Relatos de experiência). CD-Rom.

TRASK, R. L. Dicionário de linguagem de lingüistica. Tradução de Rodolfo Ilari. São Paulo: Contexto, 2004.

ZILBERMAN, R.; SILVA, E. T. da. Pedagogia da leitura: movimento e história. In: São Paulo: Ática, 2000. (Org.). Leitura: perspectivas interdisciplinares. 5. ed. 